\title{
Birth weight-for-gestational age is associated with DNA methylation at birth and in childhood
}

Golareh Agha ${ }^{1 * \dagger} \mathbb{D}$, Hanine Hajj ${ }^{2+}$, Sheryl L. Rifas-Shiman³, Allan C. Just ${ }^{4}$, Marie-France Hivert ${ }^{3,5}$, Heather H. Burris ${ }^{6,7}$, Xihong Lin ${ }^{8}$, Augusto A. Litonjua ${ }^{9}$, Emily Oken ${ }^{3}$, Dawn L. DeMeo ${ }^{10}$, Matthew W. Gillman ${ }^{3,11}$ and Andrea A. Baccarelli ${ }^{1}$

\begin{abstract}
Background: Both higher and lower fetal growth are associated with cardio-metabolic health later in life, suggesting that prenatal developmental programming determines long-term cardiovascular disease risk. Epigenetic mechanisms, which orchestrate fetal growth and development, may offer insight on the early programming of health and disease. We investigated whether birth weight-for-gestational is associated with DNA methylation at birth and mid-childhood, measured via the Infinium 450K array.

Methods/results: Participants were from Project Viva, a pre-birth cohort of pregnant women and their children in Eastern Massachusetts. After exclusion of participants with maternal type 1 or 2 diabetes and gestational age <34 weeks, we used DNA methylation assays from 476 venous umbilical cord blood samples and a subset of 235 who additionally had peripheral blood samples available in mid-childhood (age 7-10 years). Among 392,918 CpG sites analyzed, birth weight-for-gestational age $z$-score was associated with cord blood DNA methylation at $34 \mathrm{CpGs}$ (false discovery rate $P<0.05)$, after adjusting for maternal age, race/ethnicity, education, smoking, parity, delivery mode, pre-pregnancy BMI, gestational diabetes status, child sex, and estimated cord blood cell proportions based on a cord blood reference panel. Two of these CpGs were previously reported in epigenome-wide analyses of birth weight, and several other CpGs map to genes relevant to fetal growth and development. Namely, higher birth weight-for-gestational age was associated with higher methylation at four CpGs at the PBX1 locus (e.g., $\beta(95 \%$ Cl) for lead signal at cg06750897= $1.9(1.2,2.6)$ ), which encodes a transcription factor that regulates embryonic development. Birth weight-for-gestational age was also associated with mid-childhood blood DNA methylation at four of the 34 CpGs identified in cord blood analyses, including sites at the PBX1 locus described.
\end{abstract}

Conclusions: We identified CpG sites where birth weight-for-gestational age was associated with DNA methylation at birth, and for a subset of these sites, birth weight-for-gestational age was also associated with DNA methylation at mid-childhood.

Keywords: Epigenetics, DNA methylation, Birth weight

\footnotetext{
*Correspondence: Golareh.agha@columbia.edu; Golareh.agha@gmail.com

${ }^{\dagger}$ Equal contributors

'Department of Environmental Health Sciences, Mailman School of Public

Health, Columbia University, 722 West 168th Street, New York, NY 10032,

USA

Full list of author information is available at the end of the article
} 


\section{Background}

Fetal growth predicts both short- and long-term health, including cardio-metabolic health. Low birth weight has been associated with higher blood pressure, insulin resistance, type 2 diabetes, coronary heart disease events, and cardiovascular mortality later in life [1-4], and there is strong evidence that these associations are particularly due to impaired fetal growth $[5,6]$. Conversely, studies of high birth weight have shown an association with higher subsequent risk of obesity [7, 8]. The link between fetal growth and later life cardio-metabolic events remains poorly understood. Identification of molecular markers that are measured early and persist over time may provide insight into developmental origins of chronic cardio-metabolic diseases.

Epigenetic mechanisms such as DNA methylation play a central role in fetal growth and development [9]. Furthermore, an adverse in utero environment can influence establishment of epigenetic patterning and affect fetal development $[10,11]$. Several studies have shown associations between DNA methylation patterns and exposures during the in utero period, such as maternal famine, smoking, and diet [12-16]. Therefore, DNA methylation patterns associated with an indicator of fetal growth, such as birth weight adjusted for gestational age, may serve as epigenetic markers of an adverse fetal environment and help elucidate the early programming of associated cardio-metabolic risk.

A handful of initial studies in humans have revealed associations between birth weight and DNA methylation [17-21]. These past studies have either mainly focused on targeted genomic regions, have been relatively small in size, have not adequately accounted for gestational age, or have looked at DNA methylation at only one time point. More recently, Engel et al. performed a comprehensive epigenome-wide scale analyses in a large homogeneous Norwegian study population from the MoBa cohort, and reported associations of birth weight (independent of gestational age) with cord blood DNA methylation at $19 \mathrm{CpG}$ sites [22]. However, their study also examined DNA methylation at only one time point.

If DNA methylation is a stable marker of fetal programming, then the association of fetal growth with DNA methylation patterns might be expected to persist over time. In the longitudinal ALSPAC cohort in South West England, birth weight (independent of gestational age) was associated with cord blood DNA methylation in $23 \mathrm{CpG}$ sites [23]. The investigators further used longitudinal analyses and observed that methylation levels changed at the majority of these sites, concluding that birth weight-associated differential methylation does not persist with time. However, other data provide evidence that suggests persistence of DNA methylation effects in response to in utero environmental conditions. In samples collected 60 years after the Dutch Hunger Winter, there were DNA methylation differences between individuals who were prenatally exposed to in utero famine in comparison to their unexposed samesex siblings [12]. These DNA methylation changes were observed in biological pathways related to growth and metabolism and in genes associated with birth weight [24]. Currently, whether associations of fetal growth with DNA methylation persist over time remains an open question.

Finally, it is important to note that prior epigenetic association studies in cord blood have made statistical adjustments for cell type proportions using an adult peripheral blood methylation reference panel [22, 23]. However, this may not be appropriate for epigenetic studies of cord blood [25]. According to recent evidence, the distribution [26] and methylation profiles [27] of cord blood cell types are distinct and differ from blood at later ages. This is particularly the case for nucleated red blood cells (nRBCs), which are commonly present only in cord blood, and also appear in buffy coat isolated from cord blood. Thus, it is important to account for cord blood cell type proportions in epigenome-wide analyses by using an appropriate reference panel.

We conducted an epigenome-wide DNA methylation analysis to examine the extent to which birth weight-forgestational age (BW/GA) is associated with DNA methylation at birth, using cord blood DNA methylation profiles in 476 individuals from the Project Viva cohort. We adjusted for cord blood cell type proportions using the cord blood methylation reference panel recently made available by Bakulski et al. [27], which was also recently validated against directly measured cell type composition in cord blood [28]. For CpG sites where $\mathrm{BW} / \mathrm{GA}$ was associated with cord blood DNA methylation, we further investigated the extent to which BW/ GA was associated with peripheral blood DNA methylation at mid-childhood.

\section{Methods \\ Study population}

Study participants were from Project Viva, a prospective observational cohort study in Eastern Massachusetts that recruited pregnant women from 1999 to 2002 [29]. Research personnel recruited women at their first prenatal visit at one of eight obstetric offices of Atrius Harvard Vanguard Medical Associates, a multi-specialty group practice. Eligibility requirements were the ability to answer questions in English, at $<22$ weeks of gestation at study entry, and a singleton pregnancy. All women provided written informed consent, and institutional review boards of participating institutions approved the study [29]. Of 2218 live births, we collected 1018 venous umbilical cord blood samples at the time of delivery. Of 
these, cord blood DNA methylation assays were completed in 2014 for 507 Viva infants with genetic consent, of whom 22 were excluded due to low quality or irreconcilable sample swaps. Among remaining participants $(n=485)$, we excluded infants if mothers had type 1 diabetes $(n=1)$, type 2 diabetes $(n=1)$, missing covariate info ( $n=1$ missing pre-pregnancy body mass index, $\mathrm{BMI})$, or if the infant's gestational age at delivery was $<34$ weeks $(n=6)$. The final analytic sample for cord blood analyses was 476 . Of these 476 participants, 235 also had DNA methylation samples (assayed concurrently with cord blood samples) from mid-childhood (mean 7.9 years, range 6.7-10.5 years) peripheral white blood cells.

\section{Ascertainment of birth data and measurement of birth weight-for-gestational age}

We obtained infant birth weight in grams and date of delivery from hospital medical record. We calculated length of gestation in days by subtracting the date of the last menstrual period (LMP) from the date of delivery. If gestational age according to the second-trimester ultrasound differed from that according to the LMP by $>10$ days, we used ultrasound dating to determine gestational age. We determined sex-specific BW/GA $z$-scores from a US national reference [30].

\section{Covariates}

Research personnel used interviews, mailed questionnaires, and clinical records to obtain information on maternal characteristics, including race/ethnicity (nonHispanic white, black, Hispanic, Asian, or other), educational status (less than high school, high school diploma, some college, BA or BS, or graduate degree), smoking status (never, former, smoked any time during pregnancy), maternal age (reported at enrollment), maternal pre-pregnancy BMI (based on self-report at enrollment of height and pre-pregnancy weight), parity, mode of delivery (cesarean or vaginal delivery), gestational diabetes status (obtained from prenatal clinical records on maternal glucose tolerance testing; categorized as normal, isolated hyperglycemia, gestational impaired glucose tolerance, or gestational diabetes). For the current analyses, we collapsed "Asian" and "other" to include race/ ethnicity as a 4-category variable, and we dichotomized educational status as college graduate vs. not a college graduate, and parity as 0 (nulliparous) vs. 1 or more (multiparous).

\section{Measurement, filtering, and processing of DNA methylation data}

Trained medical personnel obtained venous umbilical cord blood samples immediately after delivery, which they promptly stored in a dedicated refrigerator $\left(4{ }^{\circ} \mathrm{C}\right)$ and transported for processing within $24 \mathrm{~h}$, and trained laboratory staff processed the samples on the same day. Whole blood samples were centrifuged to separate the buffy coat from plasma and red blood cells (RBCs), and the buffy coat was transferred into an RBC lysis solution to facilitate further lysis of RBCs. The solution was then centrifuged to obtain white blood cell (WBC) pellet and remove the lysis solution containing RBCs. A similar protocol was followed for peripheral blood samples at mid-childhood. DNA was extracted using the Qiagen Puregene Kit (Valencia, CA). Aliquots were then stored at $-80{ }^{\circ} \mathrm{C}$ until analysis. DNA was sodium bisulfite converted using the EZ DNA Methylation-Gold Kit (Zymo Research, Irvine, CA). We used a two-stage algorithm to randomly allocate samples to plates and chips in a manner ensuring balance by sex, and analyzed the samples using the Infinium Human Methylation450 BeadChip array (Illumina, San Diego, CA). For each CpG site, methylation $=M /(M+U+\varepsilon)$, where $M$ and $U$ refer to the average fluorescence intensity from the probe (i.e., oligonucleotide that hybridizes to the target $\mathrm{CpG}$ ) corresponding to the methylated and unmethylated target CpG, respectively, and $\varepsilon=100$ to protect against division by zero. Therefore, methylation at each $\mathrm{CpG}$ can range from 0 to 1 , with 0 indicating no methylation and 1 indicating $100 \%$ methylation.

We performed data import and pre-processing using $\mathrm{R}$ and Bioconductor package methylumi [31].

In addition to dropping low-quality samples, we excluded probes that had a detection $p$ value $>0.05$ for more than $1 \%$ of the samples (i.e., a signal was not detected from that probe). We additionally removed non-CpG probes, sex chromosome probes, and polymorphic probes (defined as SNP-overlapping probes, probes with a SNP at the target CpGs, or probes with a SNP at the base next to the target $\mathrm{CpG}$ ) with minorallele frequency (MAF) $\geq 5 \%$; based on UCSC common SNPs track for dbSNP build 137. We further removed any remaining probes that are considered crosshybridizing [32]. We applied this stringent CpGfiltering because polymorphic and cross-hybridizing probes can interfere with accurate detection of methylation levels [32]. The final number of probes included in the analyses was 392,918. We then performed background adjustment via the normal-exponential out-of-band ("noob") background correction method with dye-bias equalization [33], and further normalized using the Beta-Mixture Quantile dilation (BMIQ) approach [34]. We visually examined strip plots of control probes for bisulfite conversion and specificity, and examined density plots for the $\beta$-values across samples at each normalization step. We applied the ComBat method to adjust the methylation data for sample plate, to reduce potential for bias due to batch effects [35]. 


\section{Statistical analyses}

For epigenome-wide analyses, we logit-transformed the methylation values to obtain methylation data on the Mvalue scale; this better satisfies assumptions of linear regression and is more statistically valid for differential methylation analyses [36]. We used robust linear regression models to conduct CpG-by-CpG analyses, with logit-transformed $\mathrm{M}$-values as the dependent variable and $\mathrm{BW} / \mathrm{GA} z$-score as the continuous independent variable. Analyses were adjusted for potential confounders of the BW/GA-DNA methylation association, including maternal age (continuous), race, education, smoking status, parity, mode of delivery, pre-pregnancy BMI (continuous), gestational diabetes status, and child sex. To adjust for blood cell type proportions, we used the statistical deconvolution method of Houseman et al. [37]. For our cord blood analyses, we used a reference panel of nucleated cells isolated from cord blood [27]. We corrected for multiple testing by controlling the false discovery rate at $5 \%$, thus we considered an associations with FDR $q$ value $<0.05$ as significant.

We then conducted analyses of BW/GA $z$-score and mid-childhood peripheral blood DNA Methylation, limited to the CpGs that were significant in the cord blood analyses. Mid-childhood peripheral blood analyses were adjusted for all covariates that were included in the cord blood analyses, and additionally adjusted for childhood age at the time of blood sampling, which ranged from 6.7 to 10.5 years. We used an adult leukocyte reference panel [38] for cell type adjustment in our mid-childhood analyses on peripheral blood. Estimates of cell type proportion were included as variables directly in the regression models. While the regression analyses were conducted with DNA methylation on the M-Value scale, effect estimates in the result are reported on the original scale, for easier interpretation. Thus, effect estimates represent difference in \% methylation for a 1-unit increase in BW/GA $z$-score.

\section{Results}

Among the 476 mother-infant pairs included in these analyses, mean (SD) maternal age was 32.1 (5.4) years at enrollment in early pregnancy. Approximately $71 \%$ of women were non-Hispanic white, $11.8 \%$ AfricanAmerican, 7.8\% Hispanic, and $9.5 \%$ as other race/ethnicity (including Asian and those identifying as more than one race). Additionally, $66 \%$ of women were college graduates, $11 \%$ reported smoking during pregnancy, and $36 \%$ were overweight or obese before pregnancy. Among infants, mean (SD) birth weight was 3561 (506) g, mean (SD) BW/GA $z$-score was 0.27 (0.96); 5\% were small-for-gestational age (SGA; defined as BW/GA $<10$ th percentile) and $15 \%$ were large-for-gestational age (LGA; defined as BW/GA $\geq 90$ th percentile); $48 \%$ of infants were female.
Mothers who were overweight or obese, or were multiparous, tended to give birth to infants with higher BW/ GA (Table 1).

In epigenome-wide analyses with multi-variable adjustment, BW/GA was associated (FDR $q$ value $<0.05$ ) with cord blood DNA methylation at 34 CpG sites (Table 2). Descriptive characteristics of methylation levels at each of these sites are presented in Additional file 1. Of note, higher BW/GA was associated with higher DNA methylation at four CpGs annotated to the pre-B-cell leukemia homeobox 1 (PBX1) gene (difference in \% methylation $(95 \% \mathrm{CI})$ for a 1 -unit increment in BW/GA $z$-score $=1.9$ (1.2, 2.6), 1.9 (1.2, 2.6), $1.8(1.1,2.5)$, and $1.5(0.9,2.2)$ for cg18181229, cg06750897, cg00222472, and cg20682146, respectively; Table 2). At this $P B X 1$ locus (located on chr 1), cg06750897, cg18181229, cg00222472, and cg20682146 are all located within the same CpG-island region, within the same DNase1 hypersensitivity cluster (ENCODE data, Fig. 1). The scatterplots in Fig. 2 demonstrate linear positive associations between BW/GA and methylation values in these four $\mathrm{CpGs}$, generally with no influence from outlying observations.

In addition, we observed that BW/GA was inversely associated (FDR $q$ value $<0.05$ ) with cord blood DNA methylation at two $\mathrm{CpG}$ sites that were also previously reported [22] to show such an association: cg25953130 and cg25124943 (difference in \% methylation $(95 \% \mathrm{CI})=-2.0 \quad(-2.8,-1.2)$ for $\mathrm{cg} 25953130$ and -0.9 $(-1.3,-0.5)$ for cg25124943; Table 2).

Finally, we examined whether associations of BW/GA with DNA methylation persisted at mid-childhood. Of the 34 CpG sites where BW/GA was associated with cord blood DNA methylation at birth, associations of BW/GA with blood DNA methylation at mid-childhood remained (FDR $q$ value $<0.05$, for 34 sites tested) for four CpGs: cg26663636, cg18181229, cg00222472, and cg20682146. Notably, cg18181229, cg00222472, and cg20682146 are all annotated to $P B X 1$, the locus for which we observed multiple significant CpGs in cord blood analyses, while cg26663636 is annotated to NOS1AP. For each of these four CpGs, association of BW/GA with cord blood DNA methylation at birth was consistently in the same direction, and similar in magnitude, as association of BW/GA with peripheral blood DNA methylation at mid-childhood (e.g., difference in \% methylation $(95 \% \mathrm{CI})$ in cg20682146 $=1.5(0.9,2.2)$ at birth and $1.3(0.5,2.1)$ at mid-childhood; Fig. 3). In addition, at each site there was strong correlation between cord blood DNA methylation levels at birth and peripheral blood DNA methylation levels at mid-childhood (Fig. 4).

\section{Discussion}

In this US pre-birth cohort, birth weight-for-gestational age (BW/GA) was associated with cord blood DNA methylation at $34 \mathrm{CpG}$ sites, after adjusting for a range 
Table 1 Associations of maternal and infant characteristics with birth-weight-for-gestational-age (BW/GA) z-score in project Viva infants $(n=476)$

\begin{tabular}{|c|c|c|c|}
\hline & $N(\%)$ & $\begin{array}{l}\text { Unadjusted effect estimate } \\
(95 \% \mathrm{Cl})\end{array}$ & $\begin{array}{l}\text { Adjusted }{ }^{a} \text { effect estimate } \\
(95 \% \mathrm{Cl})\end{array}$ \\
\hline \multicolumn{4}{|l|}{ Maternal age at enrollment, years } \\
\hline$<25$ & $46(9.7)$ & $-0.57(-0.88,-0.27)$ & $-0.22(-0.56,0.13)$ \\
\hline $25-<30$ & $99(20.8)$ & $-0.10(-0.33,0.13)$ & $-0.02(-0.25,0.21)$ \\
\hline $30-<35$ & $192(40.3)$ & 0.0 (ref) & 0.0 (ref) \\
\hline $35-<40$ & $108(22.7)$ & $-0.02(-0.24,0.21)$ & $-0.09(-0.31,0.14)$ \\
\hline$\geq 40$ & $31(6.5)$ & $-0.06(-0.42,0.30)$ & $-0.14(-0.49,0.22)$ \\
\hline \multicolumn{4}{|l|}{ Maternal race/ethnicity } \\
\hline White & $338(71.0)$ & 0.0 (ref) & 0.0 (ref) \\
\hline Black & $56(11.8)$ & $-0.29(-0.56,-0.02)$ & $-0.26(-0.55,0.02)$ \\
\hline Hispanic & $37(7.8)$ & $-0.16(-0.48,0.17)$ & $-0.15(-0.48,0.18)$ \\
\hline Other & $45(9.5)$ & $-0.31(-0.61,-0.02)$ & $-0.15(-0.45,0.15)$ \\
\hline \multicolumn{4}{|l|}{ Education } \\
\hline $\begin{array}{l}\text { Less than college } \\
\text { graduate }\end{array}$ & $161(33.8)$ & $-0.16(-0.34,0.02)$ & $-0.16(-0.37,0.05)$ \\
\hline$\geq$ College graduate & $315(66.2)$ & 0.0 (ref) & 0.0 (ref) \\
\hline \multicolumn{4}{|l|}{ Maternal pre-pregnancy BMI category } \\
\hline$<18.5$ & $18(3.8)$ & $-0.40(-0.85,0.06)$ & $-0.33(-0.78,0.12)$ \\
\hline $18.5-<25$ & $285(59.9)$ & 0.0 (ref) & 0.0 (ref) \\
\hline $25-<30$ & $105(22.1)$ & $0.26(0.05,0.48)$ & $0.28(0.06,0.49)$ \\
\hline$\geq 30$ & $68(14.3)$ & $0.27(0.01,0.52)$ & $0.28(0.02,0.54)$ \\
\hline \multicolumn{4}{|l|}{ Smoking status } \\
\hline Never & $324(68.1)$ & 0.0 (ref) & 0.0 (ref) \\
\hline Former & $100(21.0)$ & $0.03(-0.18,0.25)$ & $-0.07(-0.28,0.14)$ \\
\hline During pregnancy & $52(10.9)$ & $-0.20(-0.48,0.08)$ & $-0.12(-0.41,0.17)$ \\
\hline \multicolumn{4}{|l|}{ Maternal glucose tolerance } \\
\hline Normal & $391(82.1)$ & 0.0 (ref) & 0.0 (ref) \\
\hline Isolated hyperglycemia & $45(9.5)$ & $0.28(-0.01,0.58)$ & $0.24(-0.06,0.53)$ \\
\hline Impaired glucose tolerance or gestational diabetes & $40(8.4)$ & $0.26(-0.05,0.57)$ & $0.19(-0.12,0.50)$ \\
\hline \multicolumn{4}{|l|}{ Parity } \\
\hline$\geq 1$ & $254(53.4)$ & $0.42(0.25,0.59)$ & $0.41(0.23,0.59)$ \\
\hline 0 & $222(46.6)$ & 0.0 (ref) & 0.0 (ref) \\
\hline \multicolumn{4}{|l|}{ Mode of delivery } \\
\hline Vaginal & $397(83.4)$ & $0.00(-0.24,0.23)$ & $0.04(-0.18,0.27)$ \\
\hline Cesarean section & 79 (16.6) & 0.0 (ref) & 0.0 (ref) \\
\hline \multicolumn{4}{|l|}{ Child sex } \\
\hline Male & $248(52.1)$ & $-0.07(-0.25,0.10)$ & $-0.07(-0.24,0.10)$ \\
\hline Female & $228(47.9)$ & 0.0 (ref) & 0.0 (ref) \\
\hline
\end{tabular}

${ }^{a}$ Estimates of effect were simultaneously adjusted for all other characteristics in the table

of maternal characteristics and potential biological confounders. Among the 34 sites, we identified four sites where BW/GA was also associated with peripheral blood DNA methylation at mid-childhood, in a manner similar to associations observed at birth.
BW/GA was associated with DNA methylation at birth in four CpG annotated to $P B X 1$, and for three of these sites, associations of BW/GA with DNA methylation were also present at mid-childhood. At each of these three sites, the direction and magnitude of the BW/GA- 
Table 2 Associations of birth weight-for-gestational age (BW/GA) with DNA methylation sites ${ }^{a}$ in venous umbilical cord blood at delivery, among 476 participants in Project Viva

\begin{tabular}{|c|c|c|c|c|c|}
\hline$\overline{C p G}$ site $^{\mathrm{a}}$ & $\begin{array}{l}\text { Difference in \% methylation for 1-unit } \\
\text { increment in BW/GA } z \text {-score }(95 \% \mathrm{Cl})\end{array}$ & $\begin{array}{l}\text { Nominal } \\
p \text { value }\end{array}$ & Gene $^{b}$ & Gene region $^{\mathrm{b}}$ & chr \\
\hline cg26663636 & $-0.39(-0.52,-0.25)$ & $4.31 \mathrm{E}-09$ & NOSIAP & Body & chr1 \\
\hline cg18181229 & $1.86(1.16,2.56)$ & $1.80 \mathrm{E}-07$ & $P B X 1$ & Body & chr1 \\
\hline cg06750897 & $1.93(1.22,2.64)$ & $1.83 \mathrm{E}-07$ & $P B X 1$ & Body & chr1 \\
\hline cg00222472 & $1.78(1.12,2.45)$ & $2.03 \mathrm{E}-07$ & $P B X 1$ & Body & chr1 \\
\hline cg20682146 & $1.54(0.91,2.17)$ & $1.60 \mathrm{E}-06$ & $P B X 1$ & Body & chr1 \\
\hline cg05780177 & $0.24(0.14,0.35)$ & $2.39 \mathrm{E}-06$ & DENND1B & TSS200 & chr1 \\
\hline cg00325458 & $0.1(0.06,0.14)$ & $7.27 \mathrm{E}-07$ & REL & TSS200 & chr2 \\
\hline cg23483765 & $0.22(0.14,0.31)$ & $1.15 \mathrm{E}-07$ & NIPAL4 & TSS200 & chr5 \\
\hline cg24353833 & $0.42(0.27,0.57)$ & $8.38 \mathrm{E}-08$ & NRM & Body & chr6 \\
\hline cg24641186 & $0.46(0.27,0.64)$ & $1.41 \mathrm{E}-06$ & TFAP2B & Body & chr6 \\
\hline cg20392842 & $-1.58(-2.24,-0.92)$ & $2.54 \mathrm{E}-06$ & $H L A-D M B$ & TSS200 & chr6 \\
\hline cg09364590 & $0.72(0.42,1.03)$ & $3.66 \mathrm{E}-06$ & TIAM2 & Body;TSS200 & chr6 \\
\hline cg21809331 & $0.22(0.13,0.31)$ & $2.28 \mathrm{E}-06$ & RBM28 & TSS200 & chr7 \\
\hline cg14731462 & $-0.92(-1.29,-0.55)$ & $4.20 \mathrm{E}-07$ & PTPRE & $5^{\prime}$ UTR & chr10 \\
\hline cg25953130 & $-2.01(-2.8,-1.22)$ & $7.76 \mathrm{E}-07$ & ARID5B & Body & chr10 \\
\hline cg23890469 & $0.57(0.34,0.81)$ & $1.55 \mathrm{E}-06$ & MMRN2 & Body & chr10 \\
\hline cg25124943 & $-0.92(-1.31,-0.53)$ & $2.34 \mathrm{E}-06$ & - & - & chr10 \\
\hline cg11606444 & $0.68(0.39,0.98)$ & $4.28 \mathrm{E}-06$ & SORL1 & Body & chr11 \\
\hline cg01345517 & $0.15(0.09,0.21)$ & $1.55 \mathrm{E}-06$ & DERA & Body & chr12 \\
\hline cg06648759 & $-1.08(-1.52,-0.63)$ & $2.02 \mathrm{E}-06$ & - & - & chr13 \\
\hline cg14276580 & $-0.94(-1.33,-0.54)$ & $2.24 \mathrm{E}-06$ & - & - & chr13 \\
\hline cg20549688 & $0.21(0.13,0.29)$ & $3.20 \mathrm{E}-07$ & GTF2A2 & TSS200 & chr15 \\
\hline cg21842999 & $0.51(0.3,0.72)$ & $3.20 \mathrm{E}-06$ & SHF & Body & chr15 \\
\hline cg09476997 & $1.81(1.06,2.57)$ & $2.20 \mathrm{E}-06$ & SLC9A3R2 & Body; & chr16 \\
\hline cg27283514 & $1.51(0.86,2.16)$ & $3.34 \mathrm{E}-06$ & - & - & chr16 \\
\hline cg19914554 & $0.73(0.47,0.98)$ & $2.21 \mathrm{E}-08$ & CD7 & 1stExon;5'UTR & chr17 \\
\hline cg20186396 & $0.73(0.45,1.02)$ & $3.26 \mathrm{E}-07$ & CD7 & TSS200 & chr17 \\
\hline cg14909906 & $0.17(0.1,0.25)$ & $2.37 \mathrm{E}-06$ & KDSR & 1stExon;5'UTR & chr18 \\
\hline cg23882285 & $0.12(0.07,0.17)$ & $3.37 \mathrm{E}-06$ & ROCK1 & TSS200 & chr18 \\
\hline cg23026246 & $0.13(0.08,0.19)$ & $2.23 \mathrm{E}-06$ & SPTBN4 & Body & chr19 \\
\hline cg23877608 & $0.17(0.1,0.24)$ & $2.35 \mathrm{E}-06$ & CCDC114 & TSS200 & chr19 \\
\hline cg23344780 & $-0.58(-0.83,-0.33)$ & $4.10 \mathrm{E}-06$ & EMP3 & $5^{\prime} U T R$ & chr19 \\
\hline cg04803921 & $0.13(0.08,0.19)$ & $1.68 \mathrm{E}-06$ & HM13 & Body & chr20 \\
\hline cg08422803 & $1.05(0.69,1.41)$ & 8.04E-09 & ITGB2 & TSS200;5'UTR & chr21 \\
\hline
\end{tabular}

Chr chromosome, UTR untranslated region, TSS transcription start site

${ }^{a} \mathrm{CpG}$ are ordered according to chromosome number

${ }^{b}$ Gene and gene region information are according to annotation information from Illumina. Dashed lines indicate that the CpG is annotated to an intergenic region

DNA methylation association at birth was similar to that at mid-childhood. Furthermore, the correlation between cord blood DNA methylation at birth and peripheral blood DNA methylation at mid-childhood ranged from 0.64 to 0.71 at these three sites, suggesting that methylation patterns at these sites remain relatively stable with time. PBX1 encodes a PBX homeobox family transcriptional factor, which acts as part of an important transcriptional network that regulates multiple aspects of embryonic development. Pbx1-deficient mice exhibit an embryonic lethal phenotype, characterized by defective development of the spleen, pancreas, kidney, and other 


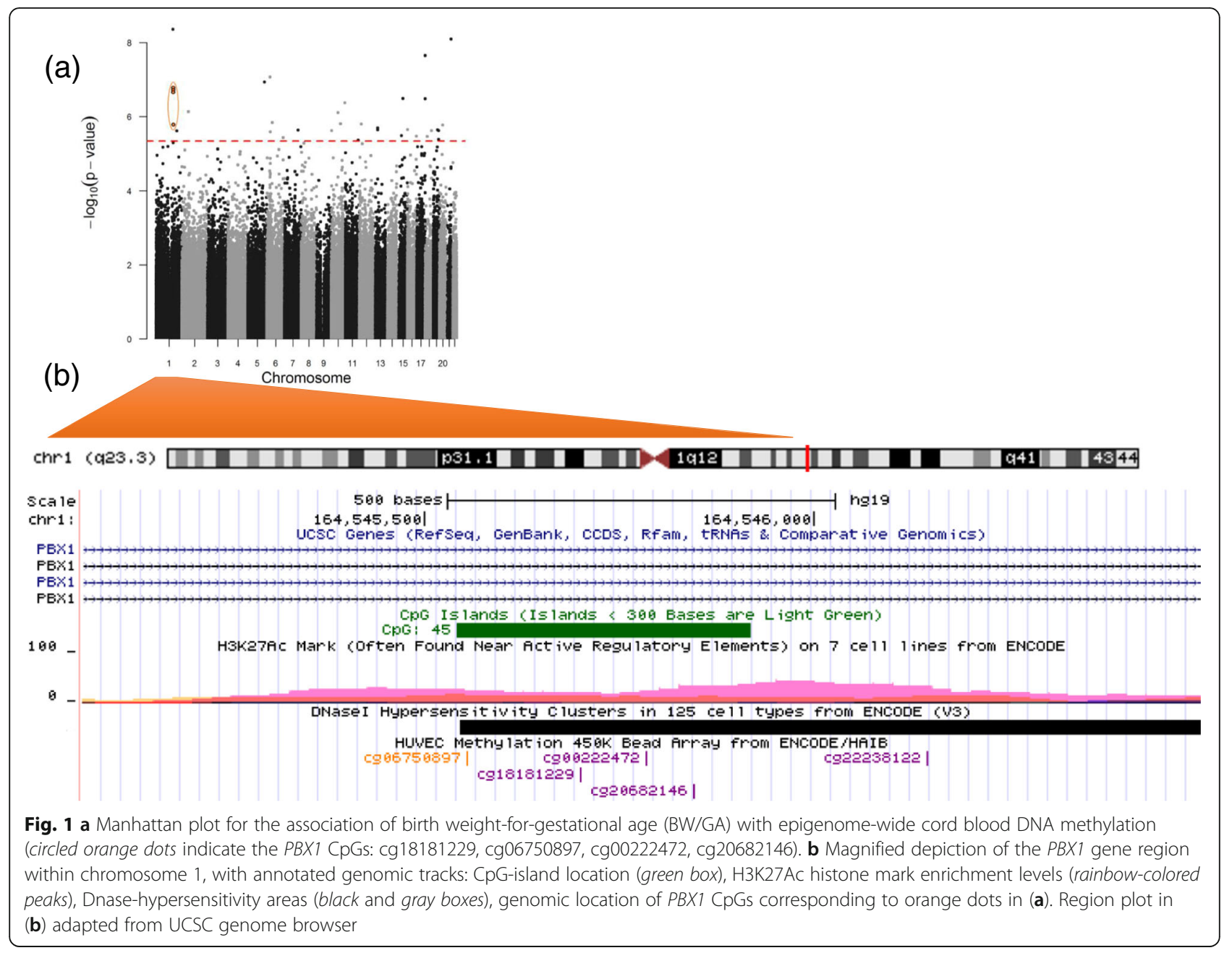

organs [39-41]. There is also evidence that pbx1 is required for skeletal patterning and programming [41], and one study found that pbx1 functions within an epigenetic complex that regulates osteoblast differentiation [42]. Specifically, targeted depletion of $P B X 1$ via short hairpin RNA (shRNA) in bone marrow stromal cells led to increased expression of bone marker genes, increased recruitment of histone acetyltransferases, and decreased H3K9 methylation, reflecting transcriptional activation [42].

Among other CpG sites where BW/GA was associated with cord blood DNA methylation, cg23882285 is annotated to Rho associated coiled-coil containing protein kinase 1 (ROCK1), which encodes a protein kinase that is a key regulator of cytoskeleton and cell polarity, and other diverse cellular processes of morphogenesis [43, 44]. Evidence from several studies in mice indicate that ROCK activity is crucial for fetal development, and that mouse spinal neurulation requires precise regulation of ROCK signaling. ROCK1 knockout mice display an embryonic lethal phenotype, and inactivation of
ROCK1 in mice has led to morphological defects and failure of neural tube closure $[45,46]$.

Two other CpG sites of interest in our cord blood findings were cg25953130 and cg25124943. Associations of birth weight (adjusted for gestational age) and cord blood DNA methylation at these two sites were also previously reported [22] in the MoBa cohort, and similar to their findings, we observed that BW/GA was inversely associated with methylation at these sites. Simpkin et al. [23] (ALSPAC cohort) also reported a similar association for cg25953130. This CpG maps to AT-rich interaction domain 5B (ARID5B), which encodes a transcriptional coactivator with a role in adipogenesis. ARID5B knockout mice are characterized by reduced lipid accumulation, lower postnatal weight, and a high rate of neonatal death [47].

Aside from the PBX1 CpG loci described above, cg26663636 was the only site at which BW/GA was associated with both cord blood and mid-childhood peripheral blood DNA methylation. This CpG is annotated to the nitric oxide synthase 1 adaptor protein (NOS1AP) 

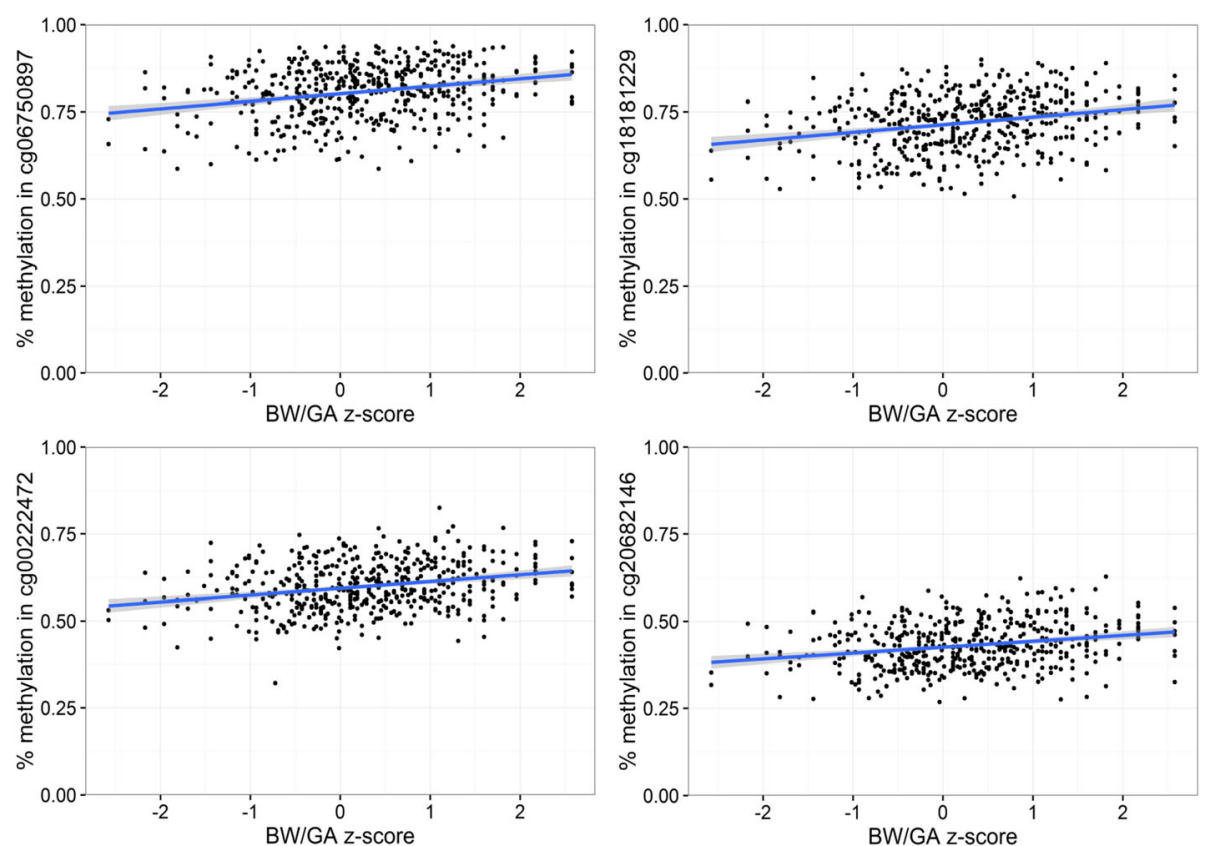

Fig. 2 Scatterplots for associations of birth weight-for-gestational-age (BW/GA) with cord blood DNA methylation at 4 CpGs mapped to the $P B X 1$ gene

locus, which encodes an adapter and regulator of the neuronal nitric oxide synthase (nNOS) enzyme implicated in modulating physiological functions such as learning, memory, and neurogenesis [48]. In addition to constituting the major source of NO in neurons, nNOS is present in skeletal muscle, cardiac muscle, and smooth muscles, where NO controls blood flow and muscle contractility. In particular, nNOS is an important cardiac protector in the heart, ensuring regulation of functions when the heart is under stress $[48,49]$.

In the ALSPAC cohort, Simpkin et al. reported that birth weight (adjusted for gestational age) was associated

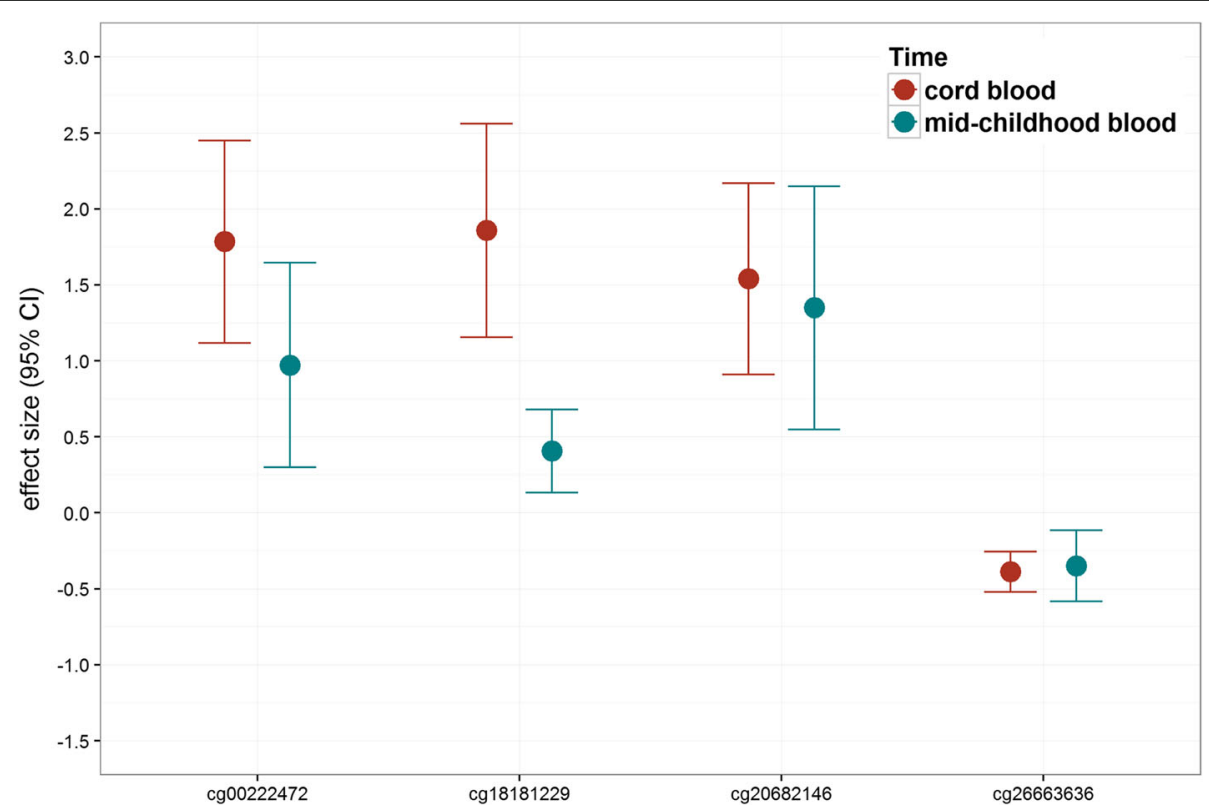

Fig. 3 Effect size comparison, for the $4 \mathrm{CpG}^{*}$ sites where birth weight-for-gestational age (BW/GA) was associated with DNA methylation both at birth (cord blood) and mid-childhood (peripheral blood). ${ }^{*}$ CpGs presented map to the following genes: PBX1 (cg18181229, cg002222472, cg20682146), NOS1AP (cg26663636) 

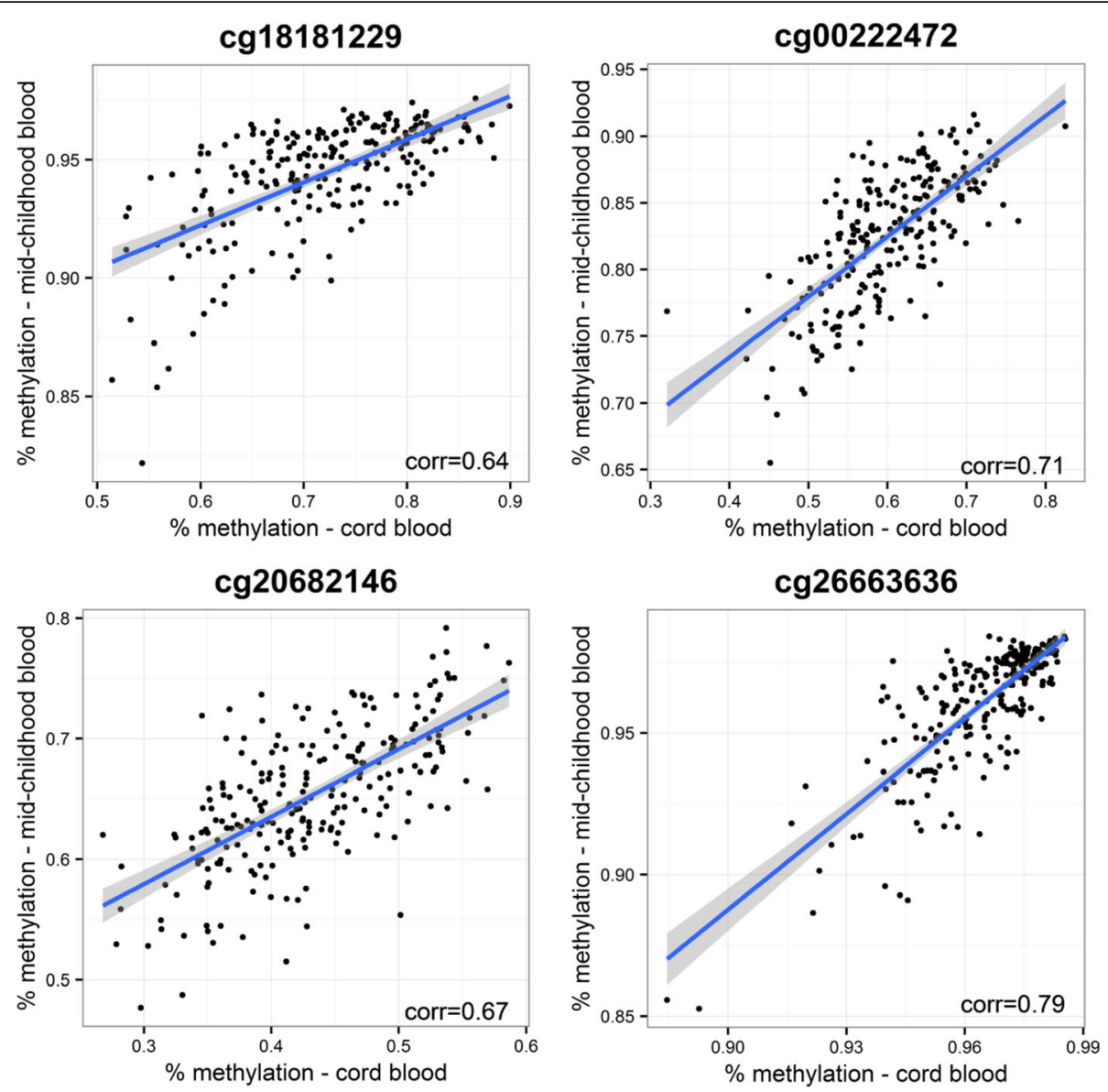

Fig. 4 Correlation between cord blood and mid-childhood blood DNA methylation for the four CpG* sites where birth weight-for-gestational age (BW/GA) was associated with DNA methylation both at birth (cord blood) and mid-childhood (peripheral blood). ${ }^{*}$ CpGs presented map to the following genes: PBX1 (cg18181229, cg00222472, cg20682146), NOS1AP (cg26663636)

with cord blood methylation in $23 \mathrm{CpG}$ sites. For these specific CpGs, they further used serially measured DNA methylation at birth, ages 7 and 17 to longitudinally model methylation changes over time. They observed that the majority of these CpGs showed marked changes in methylation levels during childhood, and that lower birth weight was associated with faster changes in methylation levels, suggesting that there is erasure of birth weight-related cord blood DNA methylation signatures with time [23]. Given that our analyses involved DNA methylation at two time points, we did not use longitudinal modeling to examine BW/GA-associated changes in methylation over time. Rather, we asked whether there were CpG sites where BW/GA was associated with DNA methylation both at birth and mid-childhood. We observed this to be the case, but only for four of the 34 sites that we tested. Thus, our results do not definitively differ from Simpkin et al.'s; rather, they suggest that persistence of associations may be dependent on specific sites examined.

Our study has several strengths. We conducted a comprehensive epigenome-wide investigation of $\mathrm{BW} / \mathrm{GA}$, the first in a relatively large sample from a US pregnancy prospective cohort. We used a nearly continuous measure of birth weight adjusted for gestational age (created using Nationwide US Natality datasets), which has the advantage of not assuming a linear relationship between birth weight and gestational age [30]. Furthermore, we examined DNA methylation at two time points. In addition, we used a cord blood reference panel to estimate cell type proportions in cord blood, reducing the possibility of reporting spurious DNA methylation associations due to varying cell type proportions. Given that contamination by nRBCs is still possible in isolated buffy coat, using a cord blood reference panel that accounts for presence of nRBCs further helps to reduce residual confounding; this is an advantage over prior cord blood epigenetic studies that have used the adult whole blood reference panel to estimate and account for cell type proportions. Although our DNA methylation analyses were on buffy coat isolated from whole cord blood, it would be interesting for future epigenetic studies to investigate methylation profiles in isolated nRBCs. Increased concentrations of $\mathrm{nRBCs}$ 
at birth have been observed in relation to maternal chronic conditions [37, 50-53] and can be predictive of child health and future neurodevelopment [54]. Thus, examining the methylation patterns in $\mathrm{nRBCs}$ may provide further insight on fetal development and later health and disease. However, isolation of DNA from nRBCs can prove challenging [27]. A limitation of our study is that the relatively higher socioeconomic status in Project Viva may reduce the generalizability of our findings. Furthermore, the Illumina Infinium $450 \mathrm{~K}$ array has until recently been the most popular and feasible choice for epigenomewide analyses; however, it approximately covers only $1.5 \%$ of genomic CpGs and is heavily geared towards coverage of gene promoter regions and protein-encoding genes [55]. The recently released $850 \mathrm{~K}$ EPIC array covers an additional 413,745 new CpG sites which are enriched in regulatory regions such and "open" chromatin regions [56]. Recent evidence highlights the important role of DNA methylation in such regulatory and non-coding genomic regions $[57,58]$ and its relevance to disease [59].

\section{Conclusions}

In conclusion, we observed that birth weight-forgestational age was associated with DNA methylation patterns at birth at select CpG sites; for several of these sites, birth weight-for-gestational age was also associated with DNA methylation at mid-childhood. We were also successful in replicating some findings from prior studies in European cohorts. Given that cardio-metabolic abnormalities associated with fetal growth often do not manifest early in life, identifying the underlying molecular markers associated with fetal growth may help to better elucidate the early development of long-term risk. Further research will better clarify the extent to which DNA methylation signatures of fetal growth and development persist with time beyond childhood, and the extent to which they are related to cardio-metabolic dysregulation.

\section{Additional file}

Additional file 1: Descriptive characteristics of methylation levels in birth weight-for-gestational age (BW/GA)-associated DNA methylation sites in venous umbilical cord blood at delivery, among 476 participants in Project Viva. (XLSX $12 \mathrm{~kb}$ )

\section{Abbreviations}

BMIQ: Beta-Mixture Quantile dilation; BW/GA: Birth weight-for-gestational age; FDR: False discovery rate; LGA: Large-for-gestational age; nRBCs: Nucleated red blood cells; SGA: Small-for-gestational age

\section{Acknowledgements}

We are indebted to the Project Viva mothers, children, and families.

\section{Funding}

This study was supported by grants from the National Institutes of Health (R01 NR013945, R01 HL111108, R01 HD 034568, K24 HD069408, K23 ES022242

\section{Availability of data and materials}

The datasets generated and analyzed during the current study are not publicly available because this study began in 1999 and we did not obtain consent for such public release of genetic data. Data are available from the corresponding author or Project Viva study team (project_viva@hphc.org) upon reasonable request.

\section{Authors' contributions}

$\mathrm{GA}, \mathrm{HH}, \mathrm{MWG}, \mathrm{EO}, \mathrm{AAB}$, and $\mathrm{HHB}$ contributed to the study conception and design. $A A B, D L D, S L R, A A L$, and MWG helped in the acquisition of data. $\mathrm{GA}, \mathrm{HH}, \mathrm{ACJ}, \mathrm{MH}, \mathrm{XL}, \mathrm{AAB}$, and $\mathrm{EO}$ performed the analysis and interpretation of data. GA and $H H$ drafted the manuscript. GA, HH, SLR, ACJ, MH, HHB, EO, $X L, A A L, D L D, M W G$, and $A A B$ are responsible for the critical revision of the manuscript for important intellectual content. GA, HH, SLR, ACJ, MH, HHB, $E O, X L, A A L, D L D, M W G$, and $A A B$ approval of final manuscript draft.

\section{Competing interests}

The authors declare that they have no competing interests.

\section{Consent for publication}

Not applicable

\section{Ethics approval and consent to participate}

All women provided written informed consent, and institutional review boards of participating institutions approved the study.

\section{Author details}

${ }^{1}$ Department of Environmental Health Sciences, Mailman School of Public Health, Columbia University, 722 West 168th Street, New York, NY 10032, USA. 'Division of Newborn Medicine, Boston Children's Hospital, Boston, MA, USA. ${ }^{3}$ Obesity Prevention Program, Department of Population Medicine, Harvard Medical School and Harvard Pilgrim Health Care Institute, Boston, MA, USA. ${ }^{4}$ Department of Preventive Medicine, Icahn School of Medicine at Mount Sinai, New York, NY, USA. 5 Diabetes Unit, Massachusetts General Hospital, Boston, MA, USA. ${ }^{6}$ Department of Neonatology, Beth Israel Deaconess Medical Center, Department of Pediatrics, Harvard Medical School, Boston, MA, USA. 7Department of Environmental Health, Harvard T.H. Chan School of Public Health, Boston, MA, USA. ${ }^{8}$ Department of Biostatistics, Harvard T.H. Chan School of Public Health, Boston, MA, USA. ${ }^{9}$ Channing Laboratory, Brigham and Women's Hospital, Boston, MA, USA. ${ }^{10}$ Channing Division of Network Medicine, Brigham and Women's Hospital, Harvard Medical School, Boston, MA, USA. ${ }^{11}$ Department of Nutrition, Harvard T.H. Chan School of Public Health, Boston, MA, USA.

Received: 30 August 2016 Accepted: 2 November 2016 Published online: 16 November 2016

\section{References}

1. Law CM, Shiell AW, Newsome CA, Syddall HE, Shinebourne EA, Fayers PM, et al. Fetal, infant, and childhood growth and adult blood pressure: a longitudinal study from birth to 22 years of age. Circulation. 2002;105: 1088-92.

2. Martyn CN, Barker DJ. Reduced fetal growth increases risk of cardiovascular disease. Health Rep. 1994;6:45-53.

3. Mzayek F, Hassig S, Sherwin R, Hughes J, Chen W, Srinivasan S, et al. The association of birth weight with developmental trends in blood pressure from childhood through mid-adulthood: the Bogalusa Heart study. Am J Epidemiol. 2007;166:413-20.

4. Whincup PH, Kaye SJ, Owen CG, Huxley R, Cook DG, Anazawa S, et al. Birth weight and risk of type 2 diabetes: a systematic review. JAMA. 2008; 300:2886-97.

5. Barker DJ. The origins of the developmental origins theory. J Intern Med. 2007:261:412-7.

6. Leon DA, Lithell HO, Vagero D, Koupilova I, Mohsen R, Berglund L, et al. Reduced fetal growth rate and increased risk of death from ischaemic heart disease: cohort study of 15000 Swedish men and women born 1915-29. BMJ. 1998;317:241-5.

7. Oken E, Gillman MW. Fetal origins of obesity. Obes Res. 2003;11:496-506.

8. Yu ZB, Han SP, Zhu GZ, Zhu C, Wang XJ, Cao XG, et al. Birth weight and subsequent risk of obesity: a systematic review and meta-analysis. Obesity Rev. 2011;12:525-42. 
9. Smith ZD, Meissner A. DNA methylation: roles in mammalian development. Nat Rev Genet. 2013;14:204-20.

10. Fleisch AF, Wright RO, Baccarelli AA. Environmental epigenetics: a role in endocrine disease? J Mol Endocrinol. 2012:49:R61-7.

11. Gluckman PD, Hanson MA. Developmental and epigenetic pathways to obesity: an evolutionary-developmental perspective. Int J Obes (Lond). 2008; 32 Suppl 7:S62-71.

12. Heijmans BT, Tobi EW, Stein AD, Putter H, Blauw GJ, Susser ES, et al. Persistent epigenetic differences associated with prenatal exposure to famine in humans. Proc Natl Acad Sci U S A. 2008;105:17046-9.

13. Lee HS, Barraza-Villarreal A, Biessy C, Duarte-Salles T, Sly PD, Ramakrishnan U, et al. Dietary supplementation with polyunsaturated fatty acid during pregnancy modulates DNA methylation at IGF2/H19 imprinted genes and growth of infants. Physiol Genomics. 2014;46:851-7.

14. Vucetic Z, Kimmel J, Totoki K, Hollenbeck E, Reyes TM. Maternal high-fat diet alters methylation and gene expression of dopamine and opioid-related genes. Endocrinology. 2010;151:4756-64.

15. Joubert BR, Haberg SE, Nilsen RM, Wang X, Vollset SE, Murphy SK, et al. 450K epigenome-wide scan identifies differential DNA methylation in newborns related to maternal smoking during pregnancy. Environ Health Perspect. 2012:120:1425-31.

16. Joubert BR, Felix JF, Yousefi P, Bakulski KM, Just AC, Breton C, et al. DNA methylation in newborns and maternal smoking in pregnancy: genomewide consortium meta-analysis. Am J Hum Genet. 2016;98:680-96.

17. Hoyo C, Fortner K, Murtha AP, Schildkraut JM, Soubry A, Demark-Wahnefried $W$, et al. Association of cord blood methylation fractions at imprinted insulin-like growth factor 2 (IGF2), plasma IGF2, and birth weight. Cancer Causes Contr. 2012;23:635-45.

18. St-Pierre J, Hivert MF, Perron P, Poirier P, Guay SP, Brisson D, et al. IGF2 DNA methylation is a modulator of newborn's fetal growth and development. Epigenetics. 2012;7:1125-32.

19. Tobi EW, Heijmans BT, Kremer D, Putter H, Delemarre-van de Waal HA Finken MJ, et al. DNA methylation of IGF2, GNASAS, INSIGF and LEP and being born small for gestational age. Epigenetics. 2011;6:171-6.

20. Gordon L, Joo JE, Powell JE, Ollikainen M, Novakovic B, Li X, et al. Neonatal DNA methylation profile in human twins is specified by a complex interplay between intrauterine environmental and genetic factors, subject to tissuespecific influence. Genome Res. 2012;22:1395-406.

21. Turan N, Ghalwash MF, Katari S, Coutifaris C, Obradovic Z, Sapienza C. DNA methylation differences at growth related genes correlate with birth weight: a molecular signature linked to developmental origins of adult disease? BMC Med Genet. 2012:5:10.

22. Engel SM, Joubert BR, Wu MC, Olshan AF, Haberg SE, Ueland PM, et al. Neonatal genome-wide methylation patterns in relation to birth weight in the Norwegian Mother and Child Cohort. Am J Epidemiol. 2014;179:834-42.

23. Simpkin AJ, Suderman M, Gaunt TR, Lyttleton O, McArdle WL, Ring SM, et al. Longitudinal analysis of DNA methylation associated with birth weight and gestational age. Hum Mol Genet. 2015;24:3752-63.

24. Tobi EW, Goeman JJ, Monajemi R, Gu H, Putter H, Zhang Y, et al. DNA methylation signatures link prenatal famine exposure to growth and metabolism. Nat Commun. 2014;5:5592.

25. de Goede OM, Razzaghian HR, Price EM, Jones MJ, Kobor MS, Robinson WP, et al. Nucleated red blood cells impact DNA methylation and expression analyses of cord blood hematopoietic cells. Clin Epigenetics. 2015;7:95.

26. Yousefi P, Huen K, Quach H, Motwani G, Hubbard A, Eskenazi B, et al. Estimation of blood cellular heterogeneity in newborns and children for epigenome-wide association studies. Environ Mol Mutagen. 2015;56:751-8.

27. Bakulski KM, Feinberg Jl, Andrews SV, Yang J, Brown S, McKenney SL, et al. DNA methylation of cord blood cell types: applications for mixed cell birth studies. Epigenetics. 2016;11:354-62.

28. Cardenas A, Allard C, Doyon M, Houseman EA, Bakulski KM, Perron P, et al. Validation of a DNA methylation reference panel for the estimation of nucleated cells types in cord blood. Epigenetics. 2016;11:773-779. http:// www.tandfonline.com/doi/full/10.1080/15592294.2016.1233091.

29. Oken E, Baccarelli AA, Gold DR, Kleinman KP, Litonjua AA, De Meo D, et al. Cohort profile: project viva. Int J Epidemiol. 2015;44:37-48.

30. Oken E, Kleinman KP, Rich-Edwards J, Gillman MW. A nearly continuous measure of birth weight for gestational age using a United States national reference. BMC Pediatr. 2003;3:6.

31. Davis S, Du P, Bilke S, Triche T Jr., Bootwalla M. methylumi: Handle Illumina methylation data. R package version 2.16.0. 2015.
32. Chen YA, Lemire M, Choufani S, Butcher DT, Grafodatskaya D, Zanke BW, et al. Discovery of cross-reactive probes and polymorphic CpGs in the Illumina Infinium HumanMethylation450 microarray. Epigenetics. 2013;8:203-9.

33. Triche Jr TJ, Weisenberger DJ, Van Den Berg D, Laird PW, Siegmund KD. Low-level processing of Illumina Infinium DNA Methylation BeadArrays. Nucleic Acids Res. 2013;41:e90.

34. Teschendorff AE, Marabita F, Lechner M, Bartlett T, Tegner J, Gomez-Cabrero $D$, et al. A beta-mixture quantile normalization method for correcting probe design bias in Illumina Infinium 450 k DNA methylation data. Bioinformatics. 2013:29:189-96.

35. Johnson WE, Li C, Rabinovic A. Adjusting batch effects in microarray expression data using empirical Bayes methods. Biostatistics. 2007;8:118-27.

36. Du P, Zhang X, Huang CC, Jafari N, Kibbe WA, Hou L, et al. Comparison of Beta-value and $\mathrm{M}$-value methods for quantifying methylation levels by microarray analysis. BMC Bioinformatics. 2010;11:587.

37. Houseman EA, Accomando WP, Koestler DC, Christensen BC, Marsit CJ, Nelson $\mathrm{HH}$, et al. DNA methylation arrays as surrogate measures of cell mixture distribution. BMC Bioinformatics. 2012;13:86.

38. Reinius LE, Acevedo N, Joerink M, Pershagen G, Dahlen SE, Greco D, et al. Differential DNA methylation in purified human blood cells: implications for cell lineage and studies on disease susceptibility. PLoS One. 2012;7:e41361.

39. Kim SK, Selleri L, Lee JS, Zhang AY, Gu X, Jacobs Y, et al. Pbx1 inactivation disrupts pancreas development and in Ipf1-deficient mice promotes diabetes mellitus. Nat Genet. 2002:30:430-5.

40. Schnabel CA, Godin RE, Cleary ML. Pbx1 regulates nephrogenesis and ureteric branching in the developing kidney. Dev Biol. 2003;254:262-76.

41. Selleri L, Depew MJ, Jacobs Y, Chanda SK, Tsang KY, Cheah KS, et al. Requirement for Pbx1 in skeletal patterning and programming chondrocyte proliferation and differentiation. Development. 2001;128:3543-57.

42. Gordon JA, Hassan MQ, Koss M, Montecino M, Selleri L, van Wijnen AJ, et al. Epigenetic regulation of early osteogenesis and mineralized tissue formation by a HOXA10-PBX1-associated complex. Cells Tissues Organs. 2011:194:146-50

43. Matsui T, Amano M, Yamamoto T, Chihara K, Nakafuku M, Ito M, et al. Rhoassociated kinase, a novel serine/threonine kinase, as a putative target for small GTP binding protein Rho. EMBO J. 1996;15:2208-16.

44. Narumiya S, Ishizaki T, Watanabe N. Rho effectors and reorganization of actin cytoskeleton. FEBS Lett. 1997;410:68-72.

45. Escuin S, Vernay B, Savery D, Gurniak CB, Witke W, Greene ND, et al. Rhokinase-dependent actin turnover and actomyosin disassembly are necessary for mouse spinal neural tube closure. J Cell Sci. 2015:128:2468-81.

46. Laeno AM, Tamashiro DA, Alarcon VB. Rho-associated kinase activity is required for proper morphogenesis of the inner cell mass in the mouse blastocyst. Biol Reprod. 2013;89:122.

47. Whitson RH, Tsark W, Huang TH, Itakura K. Neonatal mortality and leanness in mice lacking the ARID transcription factor Mrf-2. Biochem Biophys Res Commun. 2003;312:997-1004.

48. Zhou L, Zhu DY. Neuronal nitric oxide synthase: structure, subcellular localization, regulation, and clinical implications. Nitric Oxide. 2009;20:223-30.

49. Zhang YH, Jin CZ, Jang JH, Wang Y. Molecular mechanisms of neuronal nitric oxide synthase in cardiac function and pathophysiology. J Physiol. 2014:592:3189-200.

50. Aali BS, Malekpour R, Sedig F, Safa A. Comparison of maternal and cord blood nucleated red blood cell count between pre-eclamptic and healthy women. J Obstet Gynaecol Res. 2007;33:274-8.

51. Baschat AA, Gungor S, Kush ML, Berg C, Gembruch U, Harman CR. Nucleated red blood cell counts in the first week of life: a critical appraisal of relationships with perinatal outcome in preterm growth-restricted neonates. Am J Obstet Gynecol. 2007;197:286. e1-8.

52. Yeruchimovich M, Dollberg S, Green DW, Mimouni FB. Nucleated red blood cells in infants of smoking mothers. Obstet Gynecol. 1999;93:403-6.

53. Yeruchimovich M, Mimouni FB, Green DW, Dollberg S. Nucleated red blood cells in healthy infants of women with gestational diabetes. Obstet Gynecol. 2000;95:84-6.

54. Buonocore G, Perrone S, Gioia D, Gatti MG, Massafra C, Agosta R, et al. Nucleated red blood cell count at birth as an index of perinatal brain damage. Am J Obstet Gynecol. 1999;181:1500-5.

55. Sandoval J, Heyn H, Moran S, Serra-Musach J, Pujana MA, Bibikova M, et al. Validation of a DNA methylation microarray for $450,000 \mathrm{CpG}$ sites in the human genome. Epigenetics. 2011;6:692-702. 
56. Moran S, Arribas C, Esteller M. Validation of a DNA methylation microarray for $850,000 \mathrm{CpG}$ sites of the human genome enriched in enhancer sequences. Epigenomics. 2016;8:389-99.

57. Gelfman S, Cohen N, Yearim A, Ast G. DNA-methylation effect on cotranscriptional splicing is dependent on GC architecture of the exonintron structure. Genome Res. 2013;23:789-99.

58. Lev Maor G, Yearim A, Ast G. The alternative role of DNA methylation in splicing regulation. Trends Genetics. 2015;31:274-80.

59. Reichetzeder C, Dwi Putra SE, Pfab T, Slowinski T, Neuber C, Kleuser B, et al. Increased global placental DNA methylation levels are associated with gestational diabetes. Clin Epigenetics. 2016;8:82.

Submit your next manuscript to BioMed Central and we will help you at every step:

- We accept pre-submission inquiries

- Our selector tool helps you to find the most relevant journal

- We provide round the clock customer support

- Convenient online submission

- Thorough peer review

- Inclusion in PubMed and all major indexing services

- Maximum visibility for your research

Submit your manuscript at www.biomedcentral.com/submit 